\title{
Do marketing territorial ao branding de território: concepções teóricas, análises e prospectivas para o Planalto Norte Catarinense*
}

\author{
Territorial marketing to the territorial branding: theoretical conceptions, \\ analyzes and forecasts for the north Planalto Norte Catarinense
}

\section{Du marketing teritoriale a lo branding des territoires: conceptions theoriques, analyses et perspectives ou Planalto Norte Catarinense}

Del marketing territorial al branding de territorio: concepciones teóricas, análisis y previsiones para el Planalto Norte Catarinense

\author{
Valdir Roque Dallabrida** \\ Alexandre Assis Tomporoski** \\ Mayara Rohrbacher Sakr***
}

Recebido em 16/04/2016; revisado e aprovado em 22/06/2016; aceito em 10/10/2016

DOI: http:/ / dx.doi.org/10.20435/1984-042X-2016-v.17-n.4(10)

\begin{abstract}
Resumo: Branding de Território é concebido como o processo de construção e comunicação de uma marca e da identidade de território. A região em estudo é o Planalto Norte Catarinense (SCBrasil), com o objetivo de propor indicativos que amparem processos de Branding de Território. É um estudo de caso, embasado na literatura. A imagem de "terra da erva-mate e chimarrão" é reconhecida como o elemento identitário principal de marca do território em estudo.
\end{abstract}

Palavras-chave: desenvolvimento territorial; branding de território; patrimônio territorial.

Abstract: Territorial Branding is conceived as the process of construction and communication of a brand and territory identity. The region under study is the North Plateau of Santa Catarina (SC-Brazil), with the objective of proposing indicative that support Branding Territorial processes. It is a case study, based on literature. The image of "the land of mate herb and chimarrão" is recognized as the main brand identity element of the territory under study.

Key words: territorial development; territorial branding; territorial heritage.

Résumé: Territoire Branding est conçu comme le processus de construction et de la communication d'une identité de marque de territoire. La région à l'étude est le du Plateau du Nord de Santa Catarina (SC-Brésil), avec l'objectif de proposer indiquant que s'orienter les processus de Branding Territoire. Il ne est une étude de cas, basée sur la littérature. L'image de «la terre de yerba mate chimarrão» est reconnu comme l'élément d'identité marqueur principal de l' territoire à l'étude. Mots-clés: developpement territorial; branding du territoire; patrimoine du territoire.

Resúmen: Branding de territorio se concibe como el proceso de construcción y comunicación de una marca y de la identidad del territorio. La región en estudio es el Planalto Norte Catarinense (SC-Brasil), con el objetivo de proponer indicativos de apoyo a los procesos de Branding de Territorio. Es un estudio de caso, con base en la literatura. La imagen de «la tierra de la yerba mate y chimarrão» es reconocido como el elemento principal de identidad de marca del territorio en estudio.

Palabras clave: desarrollo territorial; branding de territorio; patrimonio territorial.

\footnotetext{
* O presente artigo resulta de estudos que estão sendo realizados no processo de investigação referente ao Projeto de Pesquisa Signos Distintivos Territoriais e Indicação Geográfica: um estudo sobre os desafios e perspectivas como alternativa de Desenvolvimento Territorial, com financiamento do CNPq (Brasil). ** Universidade do Contestado, Canoinhas, Santa Catarina, Brasil.

*** Pontifícia Universidade Católica do Paraná, Curitiba, Paraná, Brasil.
} 


\section{INTRODUÇÃO}

Estratégias de promoção de lugares, tais como o Marketing Territorial, podem ser utilizadas para construir e divulgar a imagem dos territórios. Apesar de necessárias aos fins a que se destinam, quando se trata da construção da imagem identitária do território, sustentamos a tese de que tais estratégias não são suficientes, pois o processo de construção de Marca de Território pode ser considerado um estágio superior, que implica a projeção interna e externa da sua imagem, com vistas à definição do futuro desejado.

Em Sakr e Dallabrida (2015), o Marketing Territorial é apresentado como estratégia de construção e divulgação da imagem dos territórios, tendo como foco experiências de Indicação Geográfica. Mesmo reconhecendo a importância de tal abordagem, propomos aqui centrar o foco sobre Branding de Território. Inicialmente, assume-se o entendimento de Branding de Território como a construção e aplicação de uma "marca de território", o que corresponde, aproximadamente, à acepção comumente atribuída ao conceito de Place Branding, nas abordagens realizadas na literatura de língua inglesa.

Portanto propõe-se que, como condição prévia e indispensável à promoção e divulgação dos valores e atributos do território, visando à construção de sua marca - dimensão que condiz com campanhas promocionais e Marketing Territorial - é que esses atributos sejam tomados como referência, quando se trata de pensar qual padrão de desenvolvimento territorial se pretende instituir. Tais atributos territoriais são representados na acepção de patrimônio territorial (DALLABRIDA, 2016) ${ }^{1}$.

\footnotetext{
${ }^{1}$ Em Dallabrida (2015b) se utiliza o conceito capital territorial com o mesmo sentido. No entanto, atendendo a uma visão mais geográfica, se prefere o uso de patrimônio territorial, seguindo autores, como Magnaghi (2000).
}

Este texto inicia apresentando os procedimentos metodológicos. Segue com uma revisão do estado da arte sobre Branding de Território, dando destaque ao conceito de território e patrimônio territorial, sem antes deixar de rememorar o debate sobre Marketing Territorial. Para introduzir o debate empírico, relata-se, de modo sucinto, a caracterização histórica e socioeconômica de um recorte territorial estudado pelos autores recentemente, o Planalto Norte Catarinense. Na sequência, apresentam-se resultados de estudos realizados que visam identificar qual imagem de território predomina no referido recorte territorial. Nas considerações finais, amparados no estudo realizado, destacam-se tanto o desconhecimento de elementos de identidade relacionados à história regional, como o reconhecimento da região como "a terra da erva-mate e chimarrão", este último, representando, concomitantemente, potencial socioeconômico e elemento identitário em futuras estratégias para construção de marca do território.

\section{O CAMINHO METODOLÓGICO PERCORRIDO}

Resumidamente, o presente texto focaliza a revisão da literatura, relacionando-a, empiricamente, com um estudo de caso, executado na região do Planalto Norte Catarinense (PNC).

Convém destacar que pesquisas abrangentes e sistemáticas, embora desejáveis, demandam aplicações de recursos de natureza diversa e, dadas as limitações inerentes a esse processo, neste artigo, os autores optaram por executar a análise empírica mediante procedimento amostral, aplicado a um recorte territorial específico, a saber, o Planalto Norte Catarinense (PNC).

Inicia-se pela contextualização teórica dos conceitos que precedem a referência à noção sobre Branding e/ou Marketing Territorial, ou seja, a introdu- 
ção de debate sobre território, territorialidade, identidade e patrimônio territorial.

Subsequentemente, com o intuito de estabelecer uma relação empírica, utiliza-se um estudo de caso, realizado na região do Planalto Norte Catarinense (PNC), situada no centro-norte do Estado de Santa Catarina (Brasil), identificando suas especificidades, potencialidades e limites, quando da possível projeção de um processo de Branding de Território. Para tal, recorre-se a uma pesquisa realizada recentemente, mediante um inquérito aplicado a uma amostra de residentes na região. $\mathrm{O}$ estudo consistiu na elaboração e aplicação de questionários, compostos por 7 (sete) questões, sendo as 6 (seis) primeiras objetivas, de múltipla escolha, e a última questão discursiva, subjetiva e apresentada como facultativa.

Os questionários foram aplicados a 87 (oitenta e sete) alunos da Universidade do Contestado (UnC), os quais, no segundo semestre de 2015, encontravam-se cursando o Programa de Educação Superior para o Desenvolvimento Regional (PROESDE), programa instituído pelo Governo do Estado de Santa Catarina. Esses alunos, portanto, consistem na amostra selecionada para a pesquisa. Trata-se de uma amostra que consideramos significativa, pois, em função do programa de aulas, além do curso regular, eles estavam assimilando ensinamentos sobre os diferentes aspectos do desenvolvimento regional, estando distribuídos em vários municípios que compõem a região em estudo.

\section{O DEBATE TEÓRICO E CONCEITUAL}

Os conceitos de Marketing Territorial e Branding são, frequentemente, confundidos, porém é necessário entender as suas diferenças. Enquanto marketing tem relação mais com ferramentas utilizadas na promoção, o Branding está ligado à administração das marcas, tendo o intuito de criar valor e até mesmo personalidade.
Com isso, a marca, além de seu valor econômico, serve para criar laços emocionais entre a marca e o consumidor (BRITO; ZUZA, 2009).

A partir dessas reflexões, surge a ideia de Branding de Lugares (Place Branding), ou, como aqui se prefere utilizar, Branding de Território, ou seja, a criação, o fortalecimento e a divulgação da identidade ou imagem de determinado território, advinda de características únicas e diferenciais que o tornam singular perante outros.

\subsection{Questões de ordem teórica e prática que precedem a referência ao Branding}

Antes de discorrer sobre Branding, é necessário esclarecer a que nos referimos quando se utiliza a categoria conceitual território. Em Dallabrida (2006), o território é concebido como uma fração do espaço historicamente construída através das inter-relações dos atores sociais, econômicos e institucionais que atuam nesse âmbito espacial. Para o autor, as motivações que favorecem o processo de apropriação pelos atores territoriais podem ser de ordem política, social, ambiental, econômica, cultural ou religiosa, provindas do Estado, de grupos sociais ou corporativos, instituições ou indivíduos. Amparados nesse entendimento, é possível afirmar que o Estado interfere no território, mediante o exercício da sua soberania, enquanto os atores econômicos definem nele seus espaços de atuação. No entanto, para os atores sociais, o território é, principalmente, seu meio de vivência e sobrevivência.

Saquet (2015) associa-se a outros autores que consideram o território uma construção social, histórica, relacional, sempre vinculada a processos de apropriação do espaço, que atingem pessoas ou grupos sociais. Portanto, para o autor,

O território é resultado e determinante da reprodução da relação sociedade-natureza e da 
concomitante territorialização. Os territórios são produzidos espaço-temporalmente pelo exercício do poder por determinado grupo ou classe social e por suas respectivas territorialidades cotidianas. (SAQUET, 2015, p. 45).

Depreende-se que o exercício do poder ocorre por parte de quem territorializa, sejam eles, o Estado, atores econômicos ou grupos sociais, e configura os meios de vivência, de acordo com os interesses de quem lidera tais processos. Ou seja, o território é o meio em que se expressam interesses divergentes, no qual ocorre a disputa pelo poder, logo, em que se tomam decisões, frequentemente não atendendo às expectativas de todos os atores territoriais (DALLABRIDA, 2016).

A partir dessa concepção de território, emerge um elemento de complexidade ao se pensar o Branding de território: a diversidade de interesses, sobretudo aqueles antagônicos, configurada pelas relações de poder e influência. Diante de tudo isso, o que integra todos os atores territoriais, mesmo tão diferenciados em seus interesses? O elemento integrador que mais se destaca é a identidade territorial. Assim, em um contexto de competitividade global entre empresas, territórios e nações, a identidade torna-se um fator preponderante no processo comunicativo e de posicionamento de cidades, territórios e países.

A construção da identidade tem um caráter simbólico, a qual se utiliza dos fatores culturais locais relevantes e que irão prevalecer sobre outras fontes de significado já existentes. A escolha desses atributos tem relação com o que Hall (2001, p. 24) chama de "construção social da identidade". Para o autor, essa construção ocorre sempre em um contexto que é marcado por uma das três relações de poder: legitimadora, de resistência e de projeto. A essa noção estaria também relacionada à ideia de pertencimento a um lugar ou território, ou seja, a identificação de uma pessoa com um determinado grupo ou cultura.

A noção de identidade, ou mais precisamente a identidade territorial, confunde-se com elementos de ordem imaterial, como a questão da territorialidade, conforme entendida por Saquet (2015, p. 119):

\begin{abstract}
Sucintamente, as territorialidades acontecem em diferentes níveis escalares: nas famílias, nas ruas, nos bairros, nas cidades, nas "comunidades rurais", nos municípios, nos estados, nas regiões, nos países, entre países e continentes. Significa o exercício do poder, as diferenças, as identidades, as desigualdades, as linguagens, as apropriações, as redes, as representações, um híbrido de apropriações, práticas cotidianas e de interações sociais-naturais-espirituais [...].
\end{abstract}

Adicionalmente, o autor também afirma que as territorialidades envolvem concomitantemente os processos sociais e econômicos. Ou seja, não apenas a dinâmica econômica, mas também, em especial, a territorialidade plural, identifica e dimensiona um recorte espacial chamado território.

Finalmente, é possível consolidar as noções conceituais sobre território, territorialidade e identidade territorial, numa categoria conceitual abarcativa, a de patrimônio territorial, com seus diversos componentes, conforme representado na Figura 1. 


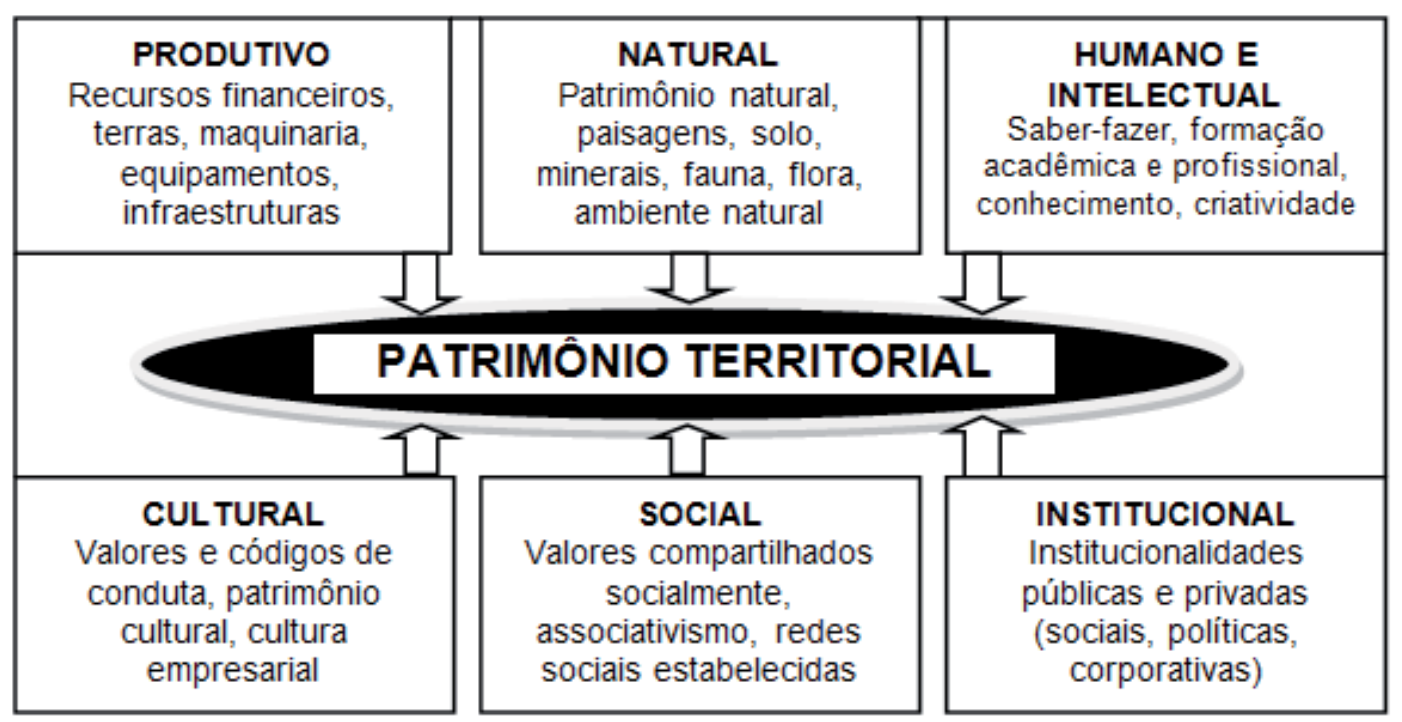

Figura 1 - Patrimônio territorial e seus componentes.

Fonte: Dallabrida (2016, p. 33).

Os componentes do patrimônio territorial são imperativos para o reconhecimento do território. Trata-se de identificar ou reconhecer os valores e atributos do território (DALLABRIDA, 2016), visando construir sua marca da forma mais adequada. Em outros termos, consiste no conjunto de ativos e recursos de um território, capazes de apoiar e revalorizar os aspectos territoriais, considerando um mundo cada vez mais tendente à homogeneização (LÓPEZ-LITA; BENLLOCH, 2005).

Ou seja, os elementos formadores do território, representados pelo seu patrimônio territorial, constituem o referencial para quaisquer tipos de intervenção territorial, em especial, quando se refere aos processos de gestão do território (DALLABRIDA, 2015b). Tais processos, considerando a diversidade de atores e interesses presentes no território, exigem a conversação social, ou o que autores preferem chamar de governança territorial (DALLABRIDA, 2015a).

Trata-se de processos desafiadores, pois precisam administrar conflitos e, ao mesmo tempo, gerar acordos, ou pactos que indiquem estratégias de futuro. Da mesma forma, são indicativos para o reconhecimento e promoção da imagem do território, em processos de Branding de Território.

\subsection{Rememorando o debate teórico sobre Marketing Territorial ${ }^{2}$}

A evolução do conceito de marketing caracteriza-se pelo fato de ampliar seu escopo, contemplando, além do setor empresarial, o âmbito social e o setor público, ou seja, instituições, cidades e territórios, visando ao diferencial competitivo e à consolidação das ferramentas de gestão.

O conceito de Marketing Territorial foi introduzido em Kotler, Haider e Rein (1993), denominado de Marketing Estratégico de Lugares, pelo qual as cidades passaram a ser comparadas a um produto para fins de análise competitiva. Essa análise competitiva do território visa posicioná-lo no mercado com um envoltório de diferenciais.

O Marketing Territorial cria, fomenta, proporciona e dinamiza o planejamento voltado ao território e aos produtos e

\footnotetext{
${ }^{2}$ Sakr e Dallabrida (2015) aprofundam o tema em questão.
} 
serviços oferecidos. Quanto a isso, Sexto et al. (2001) expõem quatro princípios básicos do Marketing de Lugares: (1) pensar e planejar o desenvolvimento a partir dos residentes, turistas e investidores; (2) promover uma análise integrada e permitir ações em perspectiva a esses públicos citados; (3) promover políticas de desenvolvimento sustentável promotoras da identificação territorial, e (4) praticar promoções com o intuito da visibilidade e notoriedade dos lugares.

Nesse sentido, o Marketing Territorial atinge seu objetivo primordial, como estratégia para garantir a diferenciação entre os locais e, consequentemente, mantê-los competitivos, seja através de seus aspectos históricos, belezas naturais, culturas populares, produtos, serviços, etc.

Tal concepção, talvez, mereça uma crítica, considerando a importância de se ressaltar que a qualidade de vida dos atores territoriais precisa estar focalizada, junto com a dinamização econômica do território, na dimensão social, cultural, política e ambiental. Nesse sentido, o Branding de Lugares, cujo conceito é analisado neste artigo, obtém seu principal emprego.

\subsection{Branding de Território}

A utilização da noção de Branding, aplicada a lugares específicos, é aqui denominada de Branding de Território, com sentido assemelhado ao que é atribuído ao conceito Place Branding na língua inglesa.

Branding é um termo oriundo da língua inglesa utilizado para descrever todas as ações relacionadas à criação e gestão de marcas. Como derivativo, Branding de Território, simplificadamente, refere-se à construção, reconhecimento e revelação, interna e externa, de uma marca de território.

No contexto da globalização contemporânea, os lugares, ou territórios, estão enfrentando enormes desafios de caráter ambiental, social, cultural e eco- nômico. Em decorrência desse fato, mais do que nunca se impõe a necessidade de um posicionamento estratégico de parte das lideranças socioeconômicas e dos gestores públicos e privados, buscando refletir sobre os ativos e recursos que constituem o patrimônio territorial do lugar onde habitam, com vistas a reconhecer ou definir democraticamente qual território somos e com qual imagem queremos que os outros nos associem. Em suma, a atitude de posicionamento estratégico dos atores territoriais, acima referida, vincula-se à construção e divulgação da marca do território. Trata-se, então, da projeção da imagem de futuro do território, como referencial estratégico para a definição do futuro desejado, como projeto político de desenvolvimento territorial (DALLABRIDA, 2015b).

\subsubsection{Marcas de Território e seu processo de construção (Branding): revisão do estado da arte e implicações de ordem operacional}

A tradução literal do termo Branding corresponde a "desenvolver uma marca" ou "construir uma marca", isto é, criar uma imagem que reforce a reputação de uma marca. Para San Eugenio (2012, p. 21), em particular,

[...] a marca de território comporta, em grande medida, a reinvenção dos lugares a partir do processo de desenvolvimento de marca (branding) com as identidades coletivas dos espaços, que se servem plenamente dos intangíveis associados às identidades territoriais.

p. 40):

Complementa San Eugenio (2012,

A marca de território, neste contexto, exerce o papel de símbolo decodificador da nova legibilidade estética de um determinado recorte territorial ou mesmo de uma necessidade de otimizar as 
virtudes de um espaço que busca comunicar de uma maneira unificada o conjunto de símbolos que o singulariza. É assim como as marcas de território se identificam e, de fato, se manifestam plenamente integradas nesta nova economia de símbolos e de espaços tão própria do capitalismo tardio.

Anholt (2007) afirma que criar uma marca de lugares (place branding) é uma das realidades comunicativas e de gestão da mercantilização dos territórios, própria da era pós-moderna. Consiste na transformação do espaço (sem simbolismos específicos) em território (imbuído de determinados valores, atributos ou significados).

No contexto de uma leitura geográfica, Muñoz (2008) refere-se ao Branding como um processo progressivo de "brandificação do território", quer dizer, a submissão dos espaços às necessidades de projeção de uma determinada imagem.

Trata-se de um processo de concreção de valores e atributos territoriais neste texto identificados pelo patrimônio territorial -, transformados na categoria de símbolos. Estamos, portanto, discorrendo acerca de uma postura pós-modernista, própria de uma economia informacional e globalizada. Em contextos dessa natureza, alguns territórios estabelecem seus parâmetros de competitividade mediante o poder de evocação de sua imagem de marca e a utilizam para se localizar no mapa dos lugares da inovação e do conhecimento (SAN EUGENIO, 2012).

Em outra publicação, San Eugenio (2013, p. 189) afirma que a competição de países, cidades e regiões, com o intuito de captar recursos, talentos, infraestruturas ou eventos, tem provocado o advento de uma luta pela singularidade, pelo reconhecimento e diferenciação, no contexto de uma emergente "economia da identidade". "Neste cenário, os espaços geográficos abdicam suas projeções ha- bituais de identidade territorial para uma recém-chegada identidade simbólica, gerida, em parte, mediante a transformação de lugares em marcas".

Para San Eugenio (2012; 2013), Branding de território põe ênfase na marca e sua capacidade para diferenciar e posicionar alguns espaços concretos, com o objetivo de projetar uma determinada imagem, principalmente ao público externo, e de atrair não apenas turistas, mas também talentos, investimentos externos e infraestruturas. Complementa o autor, afirmando que Branding de Território consiste em um novo sistema de gestão territorial baseado em critérios de eficácia, eficiência e projeção de uma imagem interna e externa. No entanto, para Anholt (2010), apesar de haver uma relação com a gestão do território, o processo de Branding implica uma nova filosofia, uma maneira de reconhecer e projetar a identidade, a imagem e a reputação de um território.

Resumindo vários autores ${ }^{3}$, San Eugenio (2012) indica os principais objetivos do Branding de Território: (1) aumentar seu atrativo como lugares de investimento empresarial; (2) melhorar sua posição competitiva no mercado turístico; (3) incrementar sua atratividade com a finalidade de captar e reter talentos; (4) fortalecer a identidade dos cidadãos com seu lugar de residência e aumentar sua autoestima; (5) obter predisposição para consumir produtos característicos de um determinado lugar; (6) obter um melhor posicionamento político e territorial de caráter estratégico; (7) facilitar o desenvolvimento do território.

No Quadro 1, faz-se uma síntese sobre a concepção de Branding de Território, a partir de autores citados por San Eugenio (2012).

\footnotetext{
3 Cabe destacar três desses autores citados por San Eugenio (2012): Fernández-Cavia (2009), López-Lita y Osuna (2005) e Moilanen e Rainisto (2009).
} 


\begin{tabular}{|l|c|}
\hline \multicolumn{1}{|c|}{ Definição } & Autor/Obra \\
\hline $\begin{array}{l}\text { Como elemento que engloba atributos diferentes de um espaço para obter um } \\
\text { determinado posicionamento, como necessidade de singularizar territórios, a } \\
\text { marca de território representa um exercício de resistência identitária, ante um } \\
\text { modelo homogeneizador inerente a uma sociedade que se autodenomina global e } \\
\text { pós-moderna. }\end{array}$ & $\begin{array}{c}\text { López-Lita } \\
\text { y Benlloch } \\
(2005)\end{array}$ \\
\hline $\begin{array}{l}\text { A marca de território deve ocupar-se da criação e comunicação de uma identidade } \\
\text { de lugar que possibilite incrementar seu atrativo. }\end{array}$ & Rainisto (2004) \\
\hline A marca de território é um grande identificador de valores intangíveis. & Morgan (2004) \\
\hline $\begin{array}{l}\text { A marca de território é a representação da identidade de um território, mediante a } \\
\text { construção de uma imagem favorável, internamente e externamente. }\end{array}$ & $\begin{array}{c}\text { Govers e Go } \\
(2009)\end{array}$ \\
\hline $\begin{array}{l}\text { Branding é concebido como um processo de representação, planejamento e } \\
\text { comunicação de um nome e da identidade de um lugar. O objetivo consiste não } \\
\text { apenas em obter rendimento econômico, mas também alcançar uma boa reputação } \\
\text { para o território. }\end{array}$ & $\begin{array}{c}\text { Anholt (2007; } \\
2010)\end{array}$ \\
\hline $\begin{array}{l}\text { Branding consiste em gerar identidade de lugar para produzir mudanças na } \\
\text { imagem e reputação, com vistas a interferir na modificação do comportamento de } \\
\text { clientes potenciais. Trata-se de uma nova forma de governança do território. }\end{array}$ & $\begin{array}{c}\text { Kavaratzis } \\
(2005)\end{array}$ \\
\hline $\begin{array}{l}\text { Branding não é uma ferramenta de gestão, senão que uma técnica de projeção de } \\
\text { uma imagem positiva dirigida a clientes potenciais. Trata-se de construir valor de } \\
\text { marca, mediante a comunicação efetiva dos atributos do território. }\end{array}$ & $\begin{array}{c}\text { Fernández- } \\
\text { Cavia (2009) }\end{array}$ \\
\hline $\begin{array}{l}\text { Apesar de integrar-se em um contexto global e pós-moderno, a marca de território } \\
\text { é, em si, um exercício de reafirmação de identidades. }\end{array}$ & $\begin{array}{c}\text { Lash e Urry } \\
\text { (1994) }\end{array}$ \\
\hline
\end{tabular}

Quadro 1 - Definições sobre Branding de Território

Fonte: Elaboração dos autores, a partir de San Eugenio (2012) ${ }^{4}$

Por outro lado, Pike (2009) menciona seis dificuldades na aplicação da teoria do Branding de lugares ou território: (1) a multidimensionalidade do território; (2) os interesses heterogêneos do público; (3) a implicação política; (4) a necessidade de gerar consensos; (5) a dificuldade de transferência do conceito de marca do sentido corporativo para o de território; (6) a disponibilidade de fundos limitados para financiamento de processos de articulação territorial.

Portanto, a marca de território, como estratégia de diferenciação, singularidade e comunicação de valores tangíveis e intangíveis, precisa ser gerida de uma forma qualificada. Ou seja, Branding de Território implica, por conseguinte, tanto em comunicação, quanto em gestão. Gestão de territórios com filosofia de Branding implica a habilitação de mecanismos, em um estágio intermediário entre a gestão pública e a gestão privada, abordando um trabalho multidisciplinar na governança do território, que contemple enlaces do tipo participativo, que ocorrem na esfera pública, com alto nível de complexidade (SAN EUGENIO, 2012), ou, mais precisamente, aquilo que é caracterizado com a concepção de governança territorial (DALLABRIDA, 2015a).

Por fim, é importante salientar que todo território possui uma determinada identidade, de forma implícita, tácita ou latente. A questão primordial é harmonizar, tanto interna, como externamente, tal identidade. "A identidade se converte um elemento de singularidade por excelência do território" (SAN EUGENIO, 2012, p. 250), cuja finalidade da promoção da identidade consiste em propiciar o desenvolvimento territorial (DALLABRIDA, 2015a/b).

\footnotetext{
4 Para acessar as obras referenciadas, consultar San Eugenio (2012), em especial, nas p. 76-79.
} 


\section{CARACTERIZAÇÃO HISTÓRICA E SOCIOECONÔMICA DO PLANALTO NORTE CATARINENSE}

A configuração da região do Planalto Norte Catarinense (PNC) decorreu de diferentes processos que convergiram para sua ocupação e colonização. Originalmente habitada por populações indígenas, dos grupos Xokleng e Kaingang, a região passou a ser intensamente entrecortada pelos tropeiros que circulavam pelo Caminho de Tropas, que permaneceu em operação desde sua abertura, no ano de 1728, até início do século XX, quando o advento das estradas de ferro resultou na decadência daqueles caminhos.

A população indígena paulatinamente miscigenou-se aos imigrantes que se assentavam no referido território, inicialmente, com lusos e espanhóis e, a partir do século XIX, com imigrantes do centro e norte da Europa, especialmente poloneses, alemães e italianos. Esse processo de miscigenação produziu um tipo específico: o caboclo, o qual é definido por suas práticas socioculturais, a despeito de sua mistura étnica (MACHADO, 2004). O caboclo ocupou as terras do planalto e ali construiu seu modo de vida, por meio da exploração da agricultura de subsistência - a roça cabocla -, da criação de animais e da exploração da erva-mate. Naquela população, desenvolveu-se uma crença religiosa caracterizada pela ausência da Igreja - enquanto instituição oficial - e pela presença de "monges" e curandeiros, os quais ministravam curas e ofereciam conselhos à população pobre.

Esse modo de vida, marcado pela simplicidade e pela harmonia com a natureza, passou sistematicamente a ser destruído pela ação dos coronéis da região - grandes proprietários rurais que açambarcavam as terras dos caboclos - e pelas empresas estrangeiras que ali se instalaram no início do século XX. A principal, a Brazil Railway Company foi contratada para construir uma linha férrea que entrecortou o território do PNC e, em consequência do decreto de concessão do direito para construção da ferrovia, constituiu uma subsidiária, a Lumber Company, com o objetivo de serrar a madeira e colonizar as terras recebidas pelo conglomerado (TOMPOROSKI, 2013).

A perda da posse da terra, o impedimento de acesso aos ervais e as inúmeras injustiças sofridas por aquela população culminaram por compeli-la à resistência, defendendo aquilo que consideravam seu e justo por direito. O resultado desse levante foi a deflagração de um dos maiores movimentos sociais da América Latina: a Guerra do Contestado (1912-1916). Após quatro anos de combates extremamente violentos, a população cabocla da região do PNC foi derrotada pelas forças legais, constituídas por mais da metade das tropas do exército brasileiro daquele período, além de contingentes das forças militares dos estados do Paraná e de Santa Catarina, bem como os vaqueanos, capangas dos coronéis da região que disponibilizaram seus homens para a implementação do que poderia se chamar de "limpeza étnica".

Porém o legado do Contestado transcendeu o período de ocorrência do conflito; transcorrido mais de um século do início dos embates, repercute naquela região. Além de um incisivo processo de concentração da propriedade da terra e da manutenção de empresas multinacionais do setor madeireiro - fatores que contribuem para a manutenção de seus municípios entre aqueles com os mais baixos indicadores de desenvolvimento do estado de Santa Catarina -, a ausência de uma identificação positiva da população com o movimento sertanejo do Contestado continua a influenciar negativamente na construção de um sentimento de pertencimento das pessoas em relação à sua história e seu território. Ou seja, a elaboração de uma identidade territorial vem sendo afetada negativamente pelo desconhecimento de sua própria história. 
O sentimento de vergonha, presente no imaginário da população do PNC muitas vezes acompanhado por uma desconfiança quase onipresente - permanece prejudicando a percepção dos valores e atributos presentes naquele território. Porém, esse processo não resultou de algo espontâneo, mas de uma estratégia política, deliberadamente implementada logo após o término do conflito, objetivando o silenciamento daqueles setores da sociedade que se envolveram ou apoiaram os caboclos. As elites latifundiárias do PNC e as oligarquias estaduais, diretamente responsáveis pelo início dos embates, promoveram uma operação de silenciamento do Contestado, pois não lhes interessava divulgar a história de um levante popular que quase derrotou os latifundiários, as oligarquias, o capital estrangeiro e os políticos republicanos que lhes davam sustentação. Consequentemente, o Contestado passou a ser visto como um movimento que envergonha a região e seu povo (TOMPOROSKI, 2013).

Contudo, nos últimos anos, novos estudos sobre o movimento sertanejo do Contestado têm expressado a complexidade e as múltiplas facetas do movimento, além de disseminar novas versões, abandonando estereótipos e preconceitos que definiam os rebeldes revoltosos como "fanáticos" ou "jagunços". Diante disso, o tema vem retomando espaço na região e atraindo visibilidade entre as novas gerações, que estão percebendo, naquele processo histórico, algo que pode ser convertido em uma "identificação positiva" da população da região com a sua própria história. Além disso, a visibilidade nacional e internacional que o tema vem obtendo, permite gradativamente reinserir o PNC em um importante circuito acadêmico, com a circulação de pesquisadores de diversas instituições de ensino superior. Por fim, e mais relevante, a retomada do debate sobre o Contestado representa enorme potencialidade para colaboração junto ao processo de cons- trução de seu desenvolvimento territorial, não apenas reconstruindo a autoestima de toda uma população, mas também atraindo visitantes que buscam compreender e rememorar aquele que foi um dos mais importantes movimentos sociais da história humana.

Desse modo, o recorte territorial do PNC, inserido no território do Contestado, apresenta-se como um importante elemento de construção da identidade territorial, por meio da reafirmação de identidades e da resistência identitária, tanto interna quanto externamente. Ao mesclar o sentimento de pertencimento de sua população a uma memória coletiva positiva, o processo histórico que constituiu a região, sempre negligenciado ou interpretado pejorativamente, detém potencial para se tornar o principal atributo cultural daquele território. Assumimos que essa hipótese de trabalho nos motivou a executar uma investigação empírica no PNC, sobre a qual se faz referência.

\section{O PLANALTO NORTE CATARINENSE: RESULTADO DE ESTUDOS TENDO COMO FOCO A ABORDAGEM TEÓRICA SOBRE BRANDING DE TERRITÓRIO}

Serão aqui expostos resultados de pesquisa realizada no segundo semestre de 2015, em municípios da região do Planalto Norte Catarinense (PNC). O estudo empírico teve dois propósitos: primeiro, buscar indícios do sentimento de identificação da população regional com o legado sócio-histórico-cultural do passado, em especial, com elementos da história do povo do Contestado; segundo, revelar a imagem identitária com a qual a população da região se reconhece. Com isso, objetivou-se identificar elementos que pudessem subsidiar futuras ações de promoção regional, por meio de estratégias de Marketing Territorial e/ou Branding de Território. Complementarmente, duas questões finais almejaram revelar o 
posicionamento dos respondentes acerca de suas percepções sobre a região, em termos de lugar para morar e padrão de desenvolvimento.

Com o intuito de facilitar a análise dos resultados, as respostas obtidas com os questionários são expostas na ordem da alternativa mais assinalada, para a menos assinalada. A primeira questão indagou a idade dos entrevistados, com o fim de conhecer o perfil dos respondentes. Dos 87 entrevistados, 31 deles responderam a essa questão. Destes, foi possível verificar que $61 \%$ possuem entre 20 e 30 anos, $23 \%$ entre 30 e 40 anos e $16 \%$ entre 40 e 60 anos.

A segunda questão procurou consultar por qual denominação os entrevistados reconheciam a região enfocada no estudo, de forma a compreender quão forte seria o sentimento de pertencimento, e sua relação com a herança sócio-histórico-cultural advinda de eventos históricos, como a Guerra do Contestado. Dos respondentes, 92\% afirmaram reconhecer a região como Planalto Norte Catarinense; $5 \%$ como Região do Contestado, e 3\% afirmaram reconhecê-la por outra denominação.

A terceira questão questionou se os entrevistados conhecem a história da região do $\mathrm{PNC}$, ou seja, se conseguiriam contá-la para as demais pessoas interessadas, no que se refere à evolução histórica e socioeconômica. Destes, 29\% responderam que sim, conhecem, porém $63 \%$ responderam que conhecem tais fatos de forma parcial, e 8\% afirmaram não conhecer. Essa questão ilustra de que forma os atores do território se identificam, ou não, com raízes sócio-histórico-culturais, o que leva à sua diferenciação perante os demais.

A quarta questão foi no sentido de compreender a identidade que o PNC deixa transcender perante seus stakeholders. Foi solicitado aos entrevistados que assinalassem até duas opções, as quais consideravam que melhor identificassem a região. A Tabela 1 demonstra a quanti- dade de respostas obtidas em cada alternativa proposta nessa questão.

A alternativa mais assinalada (55\% das respostas) diz respeito ao reconhecimento da região por "terra da erva-mate e do chimarrão", o que remete aos estudos sobre suas potencialidades como Indicação Geográfica (IG) ${ }^{5}$.

\section{Tabela 1 - Questão 4 \\ OPÇÕES QUE MELHOR IDENTIFICAM A REGIÃO}

ALTERNATIVAS VOTOS
a) Terra da erva-mate ou chimarrão;
77
b) Clima frio/temperado;
34
c) População hospitaleira;
11
d) História rica;
10
e) Natureza exuberante;
4
f) Cultura forte;
2
g) Produtos/serviços reconhecidos;
1
h) Outro;
1
i) Patrimônios materiais.
TOTAL 140

Fonte: Dados da pesquisa (2015).

A quinta questão, importante para reconhecer nos stakeholders o sentimento de pertença ao território, indagou se eles sentiam orgulho ou satisfação em habitar, e/ou estudar, e/ou trabalhar no Planalto Norte Catarinense. 61\% responderam que sim, sentem muito orgulho e satisfação, $38 \%$ responderam que sentem tais coisas parcialmente, e 1\% afirmaram não sentir.

A sexta questão, por sua vez, procurou descobrir de que forma os entrevistados percebem a região estudada, no que se refere às suas características de desenvolvimento. $65 \%$ responderam que entendem o PNC como uma região subdesenvolvida, mas com muitas potencialidades a serem exploradas; porém, 25\% a entendem como uma região estagnada,

\footnotetext{
${ }^{5}$ É uma referência ao fato de que a região está em processo de estruturação e encaminhamentos para reconhecer a erva-mate regional, como produto com Indicação Geográfica. Ver abordagem em: Dallabrida et al. (2014).
} 
com poucas perspectivas de desenvolvimento; $10 \%$ responderam que a entendem como uma região tida como desenvolvida.

Quanto à sétima questão, (subjetiva e discursiva), solicitou-se uma opinião ou um comentário referente ao assunto tratado, com o objetivo de complementar as questões anteriores. Nesta, destacam-se elogios à iniciativa da pesquisa, assim como diversas opiniões ressaltando motivos de nossa região não utilizar todo o seu potencial, enfocando, principalmente, quesitos relacionados às falhas na Administração Pública, nos âmbitos municipais e estaduais.

\section{CONSIDERAÇÕES FINAIS}

A busca pela identidade territorial se apresenta como fator preponderante para a conciliação de interesses territoriais antagônicos. A identidade territorial, intrinsecamente relacionada aos conceitos de território e territorialidade, representa um dos elementos constitutivos do patrimônio territorial, o qual permite identificar os valores e atributos do território.

Com o objetivo de enfrentar os enormes desafios de caráter ambiental, social, cultural e econômico, decorrentes da globalização contemporânea, impõe-se a necessidade de reconhecer o patrimônio territorial e, democraticamente, assumir um posicionamento estratégico amparado nos ativos e recursos do território. Como resultante, emerge naturalmente o conceito de Branding de Território, o qual permite construir a marca do território, condição prévia e indispensável à promoção e divulgação, o que faz referência ao conceito de Marketing Territorial.

Neste artigo, dada à relevância do conceito de território, opta-se por referenciar o conceito de Branding de Território, o qual se relaciona à criação e gestão de marcas, em substituição ao conceito de Place Branding. Por esse entendimento, o Branding de Território permite descrever a imagem à qual queremos que nos associem, refletindo o posicionamento estratégico obtido a partir do patrimônio territorial, divulgando a marca do território e promovendo os diferenciais que o tornam singular perante outros, no acirrado e competitivo mercado mundial.

O processo histórico de formação territorial do Planalto Norte Catarinense, permite compreender fatores que se manifestam hodiernamente e dificultam sobremaneira o desenvolvimento da região. Não obstante a luta contra o domínio fundiário e as imposições do capital estrangeiro, algumas das causas que influenciaram peremptoriamente a deflagração da Guerra do Contestado (1912-1916), ainda hoje persistem no território do PNC a concentração da propriedade da terra e a manutenção de empresas multinacionais do setor madeireiro e do tabaco. Findo o conflito bélico, os vencedores, representados pelas elites latifundiárias e as oligarquias estaduais, implementaram uma estratégia para silenciamento daqueles setores da sociedade que se envolveram no movimento sertanejo do Contestado ou apoiaram os vencidos, ou seja, os caboclos, que resistiram e lutaram por aquilo que consideravam seu e justo por direito. Esse processo continua a influenciar negativamente a construção de um sentimento de pertencimento das pessoas em relação à sua história e seu território.

Decorrente disso, a elaboração de uma identidade territorial vem sendo afetada negativamente, pelo desconhecimento de sua própria história. Assim, as recentes pesquisas acadêmicas que vêm rememorando a História do Contestado, poderão contribuir para superar o sentimento negativo e instaurar uma nova perspectiva que valorize o sentimento de pertencimento e afete positivamente a identidade territorial. No entanto há um longo caminho a ser percorrido, pois, na pesquisa realizada, apenas $29 \%$ disseram que saberiam a História, e mais de $60 \%$ afirmaram conhecê-la de forma parcial. 
O presente artigo, além de contribuir para a elucidação do debate teórico e metodológico sobre Branding de Território, propôs-se, dadas as limitações de recursos de natureza diversa, a um primeiro exercício empírico, cujos resultados foram aqui apresentados. Conquanto o estudo, futuramente, exija seu aprofundamento, através da ampliação da investigação e do dimensionamento da amostra, a pesquisa realizada nos fornece algumas evidências, considerando a perspectiva de subsidiar estratégias de Branding de Território para a região.

Em primeiro lugar, percebe-se que permanece a negação do principal elemento de identidade regional: o legado do Contestado. Dois dados corroboram essa afirmação: menos de $30 \%$ dos respondentes afirmaram conhecer a história integralmente e recontá-la; 92\% dos inquiridos disseram se reconhecer como pertencentes ao Planalto Norte Catarinense. Portanto, este se trata de um elemento de pertencimento de origem territorial.

Ademais, outros elementos identitários foram revelados pela pesquisa: primeiro, $55 \%$ dos respondentes disseram reconhecer a região pelo cultivo da erva-mate e do chimarrão; segundo, $61 \%$ disseram ter orgulho em morar, trabalhar e estudar no PNC; terceiro, 65\% dos respondentes, mesmo considerando os desafios que precisam serem superados quanto ao desenvolvimento do território do PNC, reafirmam que essa superação pode ser feita pelo melhor aproveitamento das potencialidades regionais existentes.

A partir desse cenário, torna-se possível trabalhar com a estratégia do Branding de Território, tendo como base tanto elementos de caráter intangível representados pelos laços emocionais e pelos valores expressos ao revelarem ter orgulho em relação ao território em referência - quanto pelos elementos de caráter tangível. Destes, ressalta-se o reconhecimento das potencialidades regionais, com destaque para o cultivo da erva-mate.
Assim, tanto o reconhecimento da região como "terra da erva-mate e chimarrão", quanto a perspectiva manifestada de que a superação dos desafios do desenvolvimento territorial virão em decorrência do melhor aproveitamento dos potenciais regionais inexplorados, são excelentes indicativos, manifestados na pesquisa. Com isso, a criação de uma marca de território, ou seja, uma estratégia de Branding de Território para o Planalto Norte Catarinense deve, necessariamente, considerar as duas dimensões referidas.

Esses indicativos convergem para ações em andamento no território em estudo. Dessas ações, é importante ressaltar: (i) no caso da erva-mate, o processo de reconhecimento da Indicação Geográfica, já nos seus trâmites finais; (ii) as várias estratégias que estão articuladas no âmbito de instituições públicas estaduais, a exemplo do estímulo à produção leiteira; (iii) o processo de debate regional para a proposição de um planejamento estratégico no PNC para as próximas décadas; (iv) por fim, estudos realizados no Programa de Mestrado em Desenvolvimento Regional da Universidade do Contestado, os quais apontam novas alternativas de desenvolvimento territorial, em sua maioria, voltadas à utilização sustentável de áreas subaproveitadas, nas quais prosperam remanescentes florestais nativos, poderão contribuir para a qualificação do processo produtivo da erva-mate e seu aproveitamento para a ampliação do portfólio de produtos industrializados pelas empresas ervateiras da região. Esta última, consideramos a principal entre as alternativas mencionadas.

Enfim, tomando como referência a abordagem teórica sobre Branding de Território, e sua aplicação mediante o procedimento empírico aqui relatado, constata-se que a construção, o reconhecimento e a revelação, interna e externa, de uma marca para o Planalto Norte Catarinense deveria assumir como motivação publicitária o lema "terra da erva- 
-mate e chimarrão". Essa indicação faz-se adequada à concepção de Branding de Território, bem como, é reafirmada pela pesquisa realizada, com base na amostra de população ouvida.

No entanto, como continuidade do estudo, duas questões deveriam merecer atenção: (i) a necessidade de aprofundamento dessa primeira investigação, ampliando a amostra da pesquisa, a fim de ratificar, ou negar, as evidências já reveladas; (ii) buscar mais evidências sobre a questão do desconhecimento regional em relação aos valores simbólicos e culturais da História do Contestado, buscando descobrir as reais causas, bem como as possibilidades de rememoração, na perspectiva de, também, servirem como referencial identitário no processo de construção e comunicação de uma marca e da identidade do recorte territorial do Planalto Norte Catarinense.

\section{REFERÊNCIAS}

ANHOLT, S. Competitive identitiy: the new brand management for nations, citeis and regions. Basingstoke England/Nueva Yaork: Palgrave Macmillan, 2007.

ANHOLT, S. Places: Identity, image and reputation. Reino Unido: Palgrave Macmillan, 2010.

BRITO, R. A; ZUZA, M. S. P. Branding. Revista CEPPG, Catalão, n. 21, p. 92-113, 2009.

DALLABRIDA, V. R. Território, governança e desenvolvimento territorial: indicativos teóricometodológicos, tendo a indicação geográfica como referência. São Paulo: LiberArs, 2016.

DALLABRIDA, V. R. Governança territorial: do debate teórico à avaliação da sua prática. Análise Social, Lisboa, v. 2, n. 215, p. 304-328, 2015a.

DALLABRIDA, V. R. Território. In: SIEDENBERG, D. R. (Org.). Dicionário do Desenvolvimento Regional. Santa Cruz do Sul: Editora Edunisc, 2006. p. 161-162.

DALLABRIDA, V. R. Territory Planning and Management: the theory debate in Brazil and a prospect of practice according to theoretical contributions on Territorial Governance. Revista Brasileira de Gestão e Desenvolvimento Regional, Taubaté, v. 11, n. 4, p. 51-77, 2015b.

DALLABRIDA, V. R. etal. Indicação geográfica da erva-mate no território do Contestado: reflexões e projeções. Desenvolvimento Regional em Debate, Canoinhas, v. 4, n. 2, p. 44-77, jul./ dez. 2014.

HALL, Stuart. A identidade cultural na pósmodernidade. Rio de Janeiro: DP\&A, 2001.

KOTLER, P.; HAIDER, D. H.; REIN, I. Marketing places: attracting investment, industry, and tourim to cities, states, and nations. New York: Free Press, 1993.

LÓPEZ-LITA, R.; BENLLOCH, M. T. De la marca comercial a la marca territorio. RECERCA. Revista de Pensament i Anàlise, $\mathrm{n}$. 5, p. 87-100, 2005.

MACHADO, P. P. Lideranças do Contestado: a formação das chefias caboclas (1912-1916). Campinas: Editora da Unicamp, 2004.

MAGNAGHI, Alberto. Il progetto locale. Torino: Bollati Boringhieri, 2000.

MUÑOZ, F. Urbanalización. Paisajes comunes, lugares globales. Barcelona: Gustavo Gili, 2008.

PIKE, A. Geographies of brans and branding. Progress in Human Geography, n. 33(5), p. 619645, out. 2009.

SAKR,M.R.;DALLABRIDA, V.R. Omarketing territorial como estratégia de construção e divulgação da imagem dos territórios: a indicação geográfica como referência. In: SEMINÁRIO INTERNACIONAL SOBRE DESENVOLVIMENTO REGIONAL, 7., Santa Cruz do Sul, RS, 9-11 set. 2015. Anais... Santa Cruz do Sul: UNISC, 2015.

SAN EUGENIO, V. J. Fundamentos conceptuales y teóricos para marcas de territorio. Boletín de la Asociación de Geógrafos Españoles, n. 62, p. 189-211, 2013.

SAN EUGENIO, V. J. Teoría y métodos para marcas de territorio. Barcelona: Editorial UOC, 2012.

SAQUET, M. Por uma geografia das territorialidades e das temporalidades. Uma concepção multidimensional voltada para a cooperação e para o desenvolvimento 
territorial. Rio de Janeiro: Ed. Consequência, 2015.

SEXTO, C. F.; ARCE, C. M.; VÁZQUEZ, Y. G.; VÁZQUEZ, P. G. El territorio como mercancia: fundamentos teóricos y metodológicos del marketing territorial. Revista de Desenvolvimento Econômico, n. 5, p. 68-79, dez. 2001.
TOMPOROSKI, A. A. O polvo e seus tentáculos. A Southern Brazil Lumber and Colonization Company e as transformações impingidas ao planalto contestado, 1910-1940. 2013. 282f. Tese (Doutorado em História) - Universidade Federal de Santa Catarina, Florianópolis, Santa Catarina, 2013.

\section{Sobre os autores:}

Valdir Roque Dallabrida: Geógrafo, Doutor em Desenvolvimento Regional, com atuação no Programa de Mestrado em Desenvolvimento Regional da Universidade do Contestado, Santa Catarina, Brasil. E-mail: valdirdallabrida@gmail.com

Alexandre Assis Tomporoski: Professor do Programa de Mestrado em Desenvolvimento Regional da Universidade do Contestado. Doutor em História pela UFSC. E-mail: assis.historia@gmail.com

Mayara Rohrbacher Sakr: Egressa do curso de Administração da Universidade do Contestado e Mestranda em Administração na Pontifícia Universidade Católica do Paraná, Curitiba, PR. E-mail: mayarasakr@hotmail.com 
